\title{
Analysis of Upsetting Processes BY THE Finite ELEMENT METHOD
}

\author{
CAmacho, A.M.; Marin, M.; Rubio, E.M. \& SEbastian, M.A.
}

Abstract: In this work, metal forging operations between flat parallel platens are analysed under plane strain conditions. Several parameters are considered in order to observe general trends on forces and contact pressure distributions: the friction between the die-workpiece interface $(\mu)$, the reduction in height $(r)$ and the shape factor $(h / b)$. A finite element model has been developed for obtaining platen forces and pressure distributions for different values of these parameters. Thus, forces are obtained for three reductions and different values of the friction coefficient, assuming two values of the shape factor. Otherwise, contact pressures are calculated for different values of friction, being constant the reduction and the shape factor. Besides, contact pressure distributions are compared with those obtained by an analytical method: the Slab Method. Results show the influence of the most relevant variables of this compression process on forces and die pressures.

Key words: upsetting process, plane strai, planten forces, contact pressures, Finite Element Method
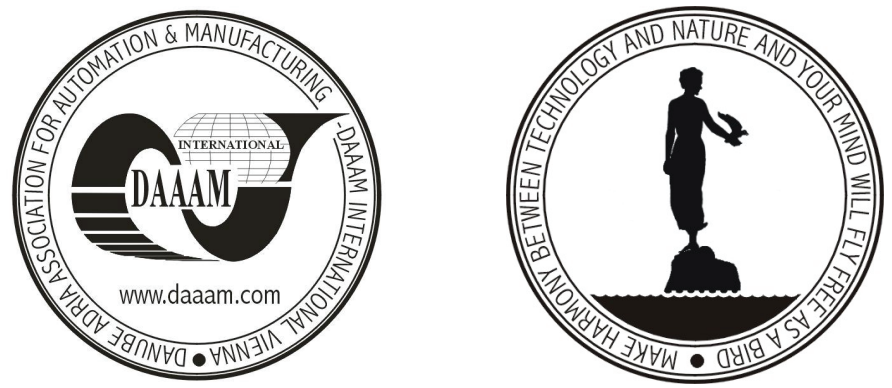

Authors' data: Assist. Prof. Dr. Camacho A.[na] M., Ph.D. Student Marin M.[arta], M. Prof. Dr. Rubio E[va] M., Prof. Dr. Sebastian M[iguel] A., Universidad Nacional de Educación a Distancia (UNED), ETS de Ingenieros Industriales; Departamento de Ingeniería de Construcción y Fabricación, Madrid, Spain, amcamacho@ind.uned.es, soldadura@ind.uned.es, erubio@ind.uned.es,msebastian@ind.uned.es

This Publication has to be referred as: Camacho, A.M.; Marin, M.; Rubio, E.M. \& Sebastian, M.A. (2006). Analysis of Upsetting Processes by the Finite Element Method, Chapter 11 in DAAAM International Scientific Book 2006, B. Katalinic (Ed.), Published by DAAAM International, ISBN 3-901509-47-X, ISSN 1726-9687, Vienna, Austria

DOI: $10.2507 /$ daaam.scibook.2006.11 